Research Article

\title{
Push-Out Tests on Large Diameter and High Strength Welded Stud Connectors
}

\author{
Fei Yang $\mathbb{D}^{1}{ }^{1}$ Yuqing Liu $\mathbb{D}^{1},{ }^{1}$ and Yongjun $\mathrm{Li} \mathbb{D}^{2}$ \\ ${ }^{1}$ Department of Bridge Engineering, Tongji University, Shanghai 200092, China \\ ${ }^{2}$ Shanghai Municipal Engineering Design Institute (Group) Co., Ltd., Shanghai 200092, China \\ Correspondence should be addressed to Yongjun Li; liyongjun@smedi.com
}

Received 13 June 2018; Accepted 27 August 2018; Published 17 September 2018

Academic Editor: Libo Yan

Copyright $(2018$ Fei Yang et al. This is an open access article distributed under the Creative Commons Attribution License, which permits unrestricted use, distribution, and reproduction in any medium, provided the original work is properly cited.

In recent years, steel-concrete composite cable-pylon anchorages are increasingly employed in the construction of long-span cable-stayed bridges, especially in China. Welded stud connectors, typically $19 \mathrm{~mm}$ and $22 \mathrm{~mm}$ in diameter, are usually densely arranged at the interface between the steel anchorage box and the wall of the concrete pylon to transfer the huge cable force into the concrete pylon. However, dense welded stud arrangements at the interface have some disadvantages, such as the shear strength reduction of stud connectors and the difficulties in arranging reinforcements and pouring pylon concrete. Larger diameter and higher strength welded studs may be excellent alternatives since they both could increase the shear strength of a single stud connector and thus reduce the required number of welded studs. In this paper, push-out tests were implemented on four groups of welded stud connector specimens, including conventional $22 \mathrm{~mm}$ welded studs, $22 \mathrm{~mm}$ welded studs with much higher strength, $25 \mathrm{~mm}$ welded studs, and $30 \mathrm{~mm}$ welded studs. The shear strength, shear stiffness, and ductility of these welded stud connectors were investigated and compared with the predictions by the equations recommended in existing design codes. The results show that the shear strength of welded stud connectors could be conservatively determined by Eurocode 4, while AASHTO LRFD will produce a suitable estimation. The load-slip relationships proposed by Ollgaard and Buttry can be used to predict the load-slip curves of large diameter and high strength welded stud connectors.

\section{Introduction}

Welded studs are the most practical connectors for achieving the composite action between steel girders and concrete slabs owing to their rapid welding technique and outstanding mechanical performance. In composite bridge superstructures, the commonly used welded studs are $19 \mathrm{~mm}$ or $22 \mathrm{~mm}$ in diameter since these welded studs are adequate to realize the full shear connection between steel girders and concrete slabs. The mechanical performance of welded studs with $19 \mathrm{~mm}$ and $22 \mathrm{~mm}$ in diameter has been investigated by many researchers. Some representative research includes the following: Ollgaard et al. [1] proposed an equation to compute the shear strength of welded studs and a curve to describe the load-slip relationship. Oehlers and Coughlan [2] put forward an empirical equation to calculate the shear stiffness of welded stud connectors. Lam [3] performed 72 static push-out tests on welded studs to determine the shear strength of welded stud connectors embedded in hollow-core slabs. Pallarés and Hajjar [4, 5] reviewed a large number of push-out and pull-out tests on welded stud connectors and proposed formulas for the limit states of welded stud connectors subjected to shear force, tension force, and combined tension and shear force. Lin et al. [6] also investigated the behavior of welded stud connectors subjected to combined tension and shear loads, and an improved shear-tension interaction strength equation was recommended.

In addition to the application in steel-concrete composite girders, welded stud connectors could also be employed in steel-concrete hybrid girders [7], steel bridges with integral abutment [8], the cable-pylon anchorage zone of cable-stayed bridges, and so on. In these composite/hybrid structures, a part of welded stud connectors will bear combined tension and shear loads, and their shear force would be much larger than in the conventional steel-concrete girders. For the 
composite cellular beams, regular circular openings are produced in the web of the steel beam by cutting and rewelding the steel sections, or by cutting circular openings in fabricated steel sections for the distribution convenience of the circular service ducts in the building structures [9]. The openings in the composite cellular beams could not only result in much larger shear force in the steel-concrete connectors compared with the conventional composite beams [9] but also cause nonnegligible pull-out tensile force in the connectors [10]. In steel-concrete composite cable-pylon anchorage structures, welded stud connectors are commonly employed to connect the steel anchor box to the concrete pylon $[11,12]$, as shown in Figure 1(a). The mechanical behavior of welded stud connectors in the cablepylon anchorage zone, as shown in Figure 1(b), has great differences compared with that at the steel-concrete interface of composite girders. The vertical component of the cable force is transferred from the steel anchor box to the wall of the concrete pylon through welded stud connectors, and this force could be extremely large in long-span cable-stayed bridges. Meanwhile, a part of welded stud connectors are under combined shear and tension loads due to the local bending moment caused by the eccentricity of the cable force at the steel-concrete interface. Therefore, welded stud connectors are commonly densely arranged at the steel-concrete interface of the cable-pylon anchorage structure to ensure the safety of the anchorage system. However, dense welded stud arrangements at the interface have some disadvantages, such as the shear strength reduction of stud connectors due to the smaller stud spacing $[13,14]$ and the difficulties in arranging reinforcements and pouring pylon concrete.

To ensure the adequate spacing among the welded studs at the steel-concrete interface of the cable-pylon anchorage system, much larger diameter and higher strength welded studs are two alternatives since they both could increase the shear strength of a single stud connector and thus reduce the required number of welded studs. Currently, almost all the push-out tests were conducted on welded stud connector specimens with diameter equal to or less than $22 \mathrm{~mm}$. Only few research papers are available focusing on the mechanical performance of large diameter welded studs, whose diameters are greater than $22 \mathrm{~mm}$. Badie et al. [15] experimentally investigated the mechanical performance of welded stud connectors with $31.8 \mathrm{~mm}$ in diameter. It was found that $31.8 \mathrm{~mm}$ stud connectors could achieve a shear capacity two times that of $22 \mathrm{~mm}$ stud connectors, while the slip at failure would decrease about 30\%. Shim et al. [16] and Lee et al. [17] performed static and fatigue push-out tests on welded stud connector specimens with $25 \mathrm{~mm}, 27 \mathrm{~mm}$, and $30 \mathrm{~mm}$ in diameter and approximately $430 \mathrm{MPa}$ in tensile strength. The test results showed that the shear strengths predicted by EN 1994-1-1 [18] and AASHTO LRFD [19] were conservative for these large stud connectors, and it was considered that the ductility of these large stud connectors was sufficient for the application in composite bridges. Nguyen and Kim [20] conducted an extensive parametric study to investigate the effect of the stud diameter and concrete strength on the shear performance of welded stud connectors. It was also concluded that the ductility of the large stud connectors was sufficient for the practical application in composite bridges. Conclusions from each researcher lack consistency for large diameter stud connectors, especially in terms of their ductility. Given that the configurations of the push-out specimens adopted by Badie et al. [15] and Shim et al. [16] were totally different, it could be inferred that the configurations of the push-out specimens might have significant effect on the ductility of larger diameter stud connector. Besides, studies on high strength studs are scarcely reported in the literature. Therefore, it is very practical to investigate the static behaviors of large diameter and high strength stud connectors in order to expand their application in steel-concrete composite/hybrid structures.

In this paper, push-out tests are implemented on four groups of welded stud connector specimens, including conventional and high strength $22 \mathrm{~mm}$ stud connector specimens and $25 \mathrm{~mm}$ and $30 \mathrm{~mm}$ stud connector specimens. The shear strength of these welded stud connectors is investigated and compared with the prediction of the design equations recommended in AASHTO LRFD [19], EN 19941-1 [18], and GB. The shear stiffness and ductility of these welded stud connectors are also examined and compared with the estimation by the existing equations. In addition, the applicability of load-slip relationships for conventional stud connectors to large diameter and high strength stud connectors is also discussed.

\section{Experimental Work}

2.1. Push-Out Specimens. Four groups of push-out specimens, denoted as SN22, SH22, SN25, and SN30, are devised in this research, and the specimens in each group are totally identical. Table 1 exhibits the main variables for each group push-out tests. Groups SN22, SN25, and SN30 specimens, with $22 \mathrm{~mm}, 25 \mathrm{~mm}$, and $30 \mathrm{~mm}$ diameter welded studs, respectively, were tested to investigate the effect of stud diameters on their shear performance. The nominal tensile strength for these three groups of welded studs is $400 \mathrm{MPa}$, which is the normal tensile strength specified in the design code. Group SH22 specimens were tested and compared with Group SN22 specimens to examine the effect of tensile strengths on their shear performance. The nominal tensile strength for this group of welded studs is $650 \mathrm{MPa}$, which is a much higher tensile strength than the conventional weld studs. The overall welded stud height is $200 \mathrm{~mm}$ for all the specimens.

Figure 2 demonstrates the configuration of the push-out specimen in this research. Each specimen consists of an assembled push-out steel member, two concrete blocks, and four welded stud connectors. The transverse spacing for welded studs is $150 \mathrm{~mm}$, and the spacing from the welded studs to the top and bottom of the concrete block both is $230 \mathrm{~mm}$. The concrete slab thickness in the specimen for standard push-out tests recommended in EN 1994-1-1 [18] is only $150 \mathrm{~mm}$, and the thinner concrete slab may result in a splitting failure mode of the concrete slab rather than the fracture of stud connectors due to the higher shear strength of large diameter and high strength stud connectors. Besides, the thickness of the concrete pylon wall, the integral concrete 


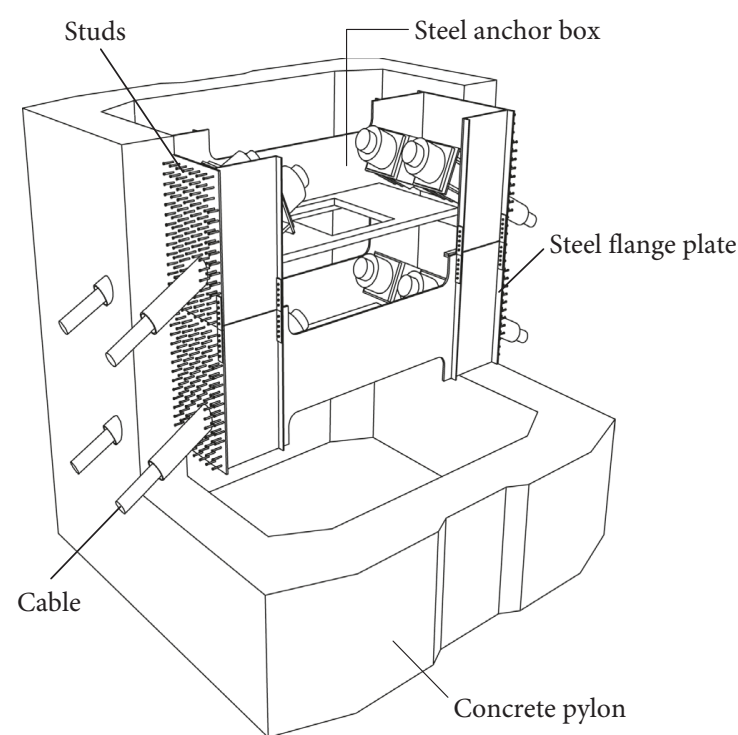

(a)

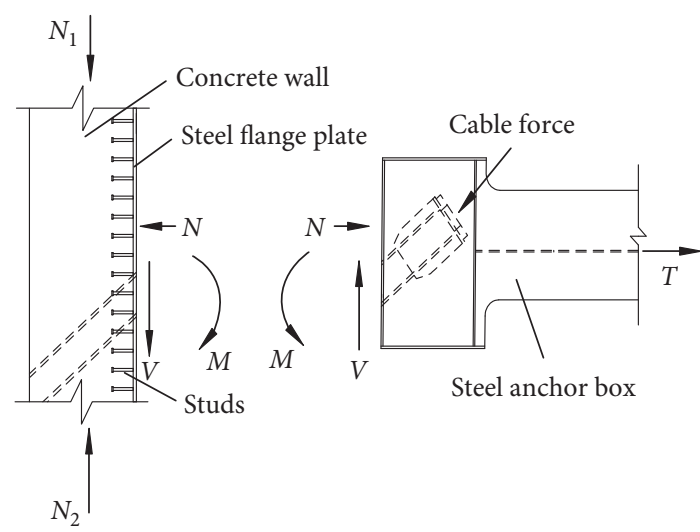

(b)

FIGURE 1: Steel-concrete composite cable-pylon anchorage. (a) Cable-pylon anchorage with steel anchor box. (b) Mechanical model of the stud connection.

TABle 1: Program of push-out tests.

\begin{tabular}{lcccc}
\hline Group & $\begin{array}{c}\text { Specimen } \\
\text { number }\end{array}$ & $\begin{array}{c}\text { Stud diameter } \\
(\mathrm{mm})\end{array}$ & $\begin{array}{c}\text { Stud tensile } \\
\text { strength }(\mathrm{MPa})\end{array}$ & $\begin{array}{c}\text { Stud height } \\
(\mathrm{mm})\end{array}$ \\
\hline SN22 & 4 & 22 & & \\
SN25 & 4 & 25 & 400 & 200 \\
SN30 & 3 & 30 & & \\
SH22 & & 22 & 650 & \\
\hline
\end{tabular}

abutment, and the concrete deck slabs in the haunch part could be at least $400 \mathrm{~mm}$. Therefore, the thickness of the concrete blocks in the push-out specimens is set to be $400 \mathrm{~mm}$, while the width and height of the concrete blocks in the push-out specimens are $460 \mathrm{~mm}$.

The steel plate thickness of the push-out steel member is $20 \mathrm{~mm}$. The height of the push-out steel member is $460 \mathrm{~mm}$, and the width of the flange and web is $350 \mathrm{~mm}$ and $220 \mathrm{~mm}$, respectively. Given that the maximum slip at the steelconcrete interface would not exceed $20 \mathrm{~mm}$, the distance from the bottom of the steel member to that of the concrete block is set to be $50 \mathrm{~mm}$. The concrete blocks were casted in the horizontal position and air-cured. Bond and friction at the interface between the steel flanges and the concrete slabs were avoided and reduced by greasing the flanges. The reinforcement diameters are $20 \mathrm{~mm}, 12 \mathrm{~mm}$, and $20 \mathrm{~mm}$ for $\mathrm{N} 1, \mathrm{~N} 2$, and N3, respectively. The fabrication process of the push-out specimens is shown in Figure 3.

2.2. Material Properties. Six concrete cubic specimens $(150 \mathrm{~mm} \times 150 \mathrm{~mm} \times 150 \mathrm{~mm})$ were cast at the same time as pouring the concrete blocks to determine material properties of the concrete. All the cubic specimens were air-cured alongside the push-out specimens. Three specimens were tested at 28th day, and the other three were tested at the test day. Table 2 summarizes the measured material properties of concrete. The nominal cubic compressive strength of the concrete is $60 \mathrm{MPa}$.

The headed studs used in Groups SN22 and SN25 were fabricated according to GB/T 10433-2002 [21]. The diameter of headed studs used in Group SN30 and the specified tensile strength used in Group SH22 exceed the limitations of the specification. Therefore, these two groups of headed studs were specially fabricated. The specified yield strengths of the stud material are $320 \mathrm{MPa}$ for Groups SN22, SN25, and SN30 and $550 \mathrm{MPa}$ for Group SH22, respectively. The actual yield strengths and ultimate strengths of the stud material were provided by the supplier. HRB335 reinforcements (with $335 \mathrm{MPa}$ nominal yield strength) and Q345C steel plates (with $345 \mathrm{MPa}$ nominal yield strength) were used in the fabrication of the push-out specimens. Three $10 \mathrm{~mm} \times 10 \mathrm{~mm} \times 50 \mathrm{~mm}$ samples of steel plate were tested under direct tension to obtain the mechanical properties, and coupon tests were performed to get the properties of the reinforcements. The mean values of the measured material properties of the studs, reinforcements, and steel plates are summarized in Table 3.

2.3. Loading Procedure and Measurement. As shown in Figure 4, the push-out specimens were tested using a hydraulic testing machine. In order to apply the load uniformly, a stiff steel transfer component was placed on the top of the push-out steel member. Fine sands were spread on the surface of the base to avoid uneven loading. Force control was adopted before $70 \%$ of the predicted failure load, and the loading rate is $6 \mathrm{kN} / \mathrm{min}$. Then, displacement control was used until the load dropped to $80 \%$ of the maximum load or failure of the specimen was observed with the loading rate equal to $0.5 \mathrm{~mm} / \mathrm{min}$. Four displacement sensors were installed at the same elevation as the welded stud connector to 


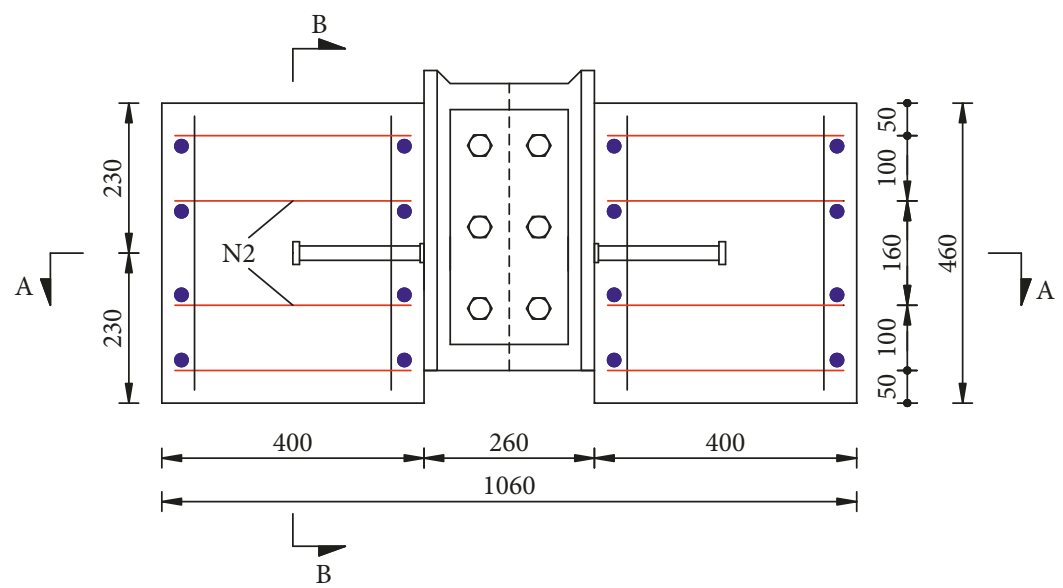

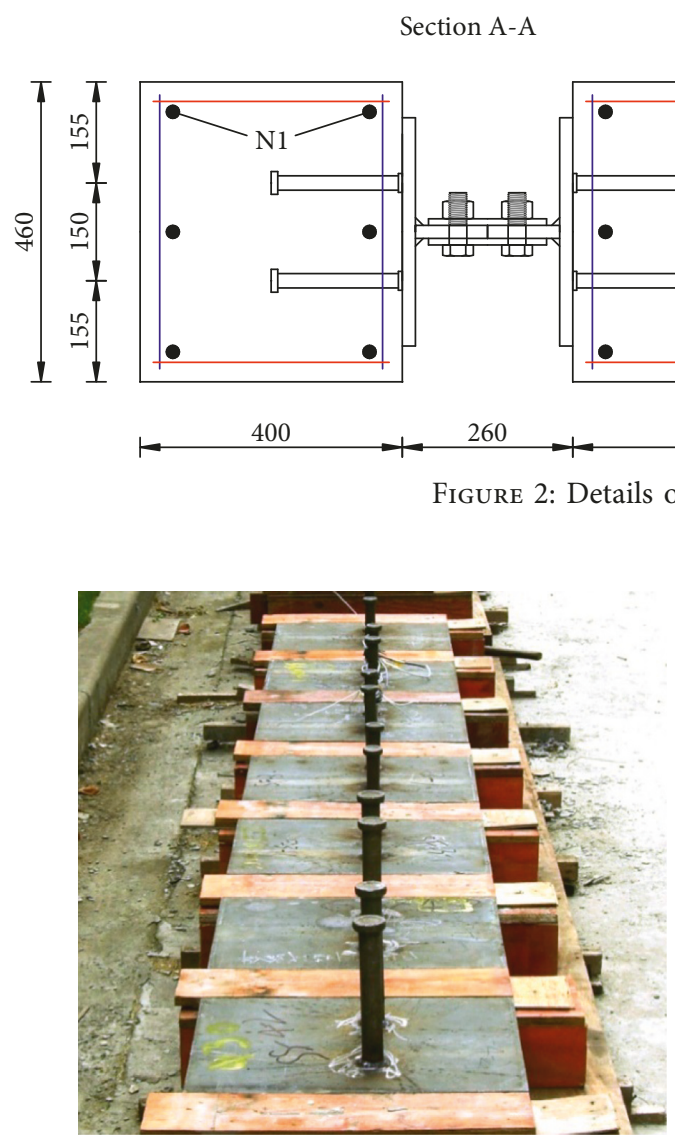

(a)
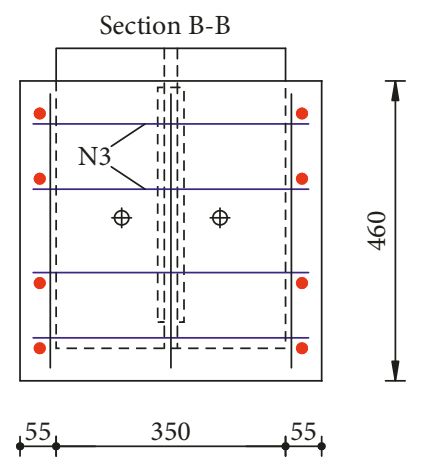

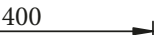


TABLe 3: Properties of steel materials (MPa).

\begin{tabular}{|c|c|c|c|c|c|}
\hline \multirow{2}{*}{\multicolumn{2}{|c|}{ Component }} & \multicolumn{2}{|c|}{ Yield strength } & \multicolumn{2}{|c|}{ Tensile strength } \\
\hline & & Nominal & Test & Nominal & Test \\
\hline \multirow{4}{*}{ Stud } & SN22 & & 385 & & 530 \\
\hline & SN25 & 320 & 380 & 400 & 485 \\
\hline & SN30 & & 375 & & 430 \\
\hline & $\mathrm{SH} 22$ & 550 & 630 & 650 & 675 \\
\hline \multicolumn{2}{|c|}{ Reinforcement } & 335 & 374 & - & 578 \\
\hline \multicolumn{2}{|c|}{ Steel plate } & 345 & 410 & - & 545 \\
\hline
\end{tabular}

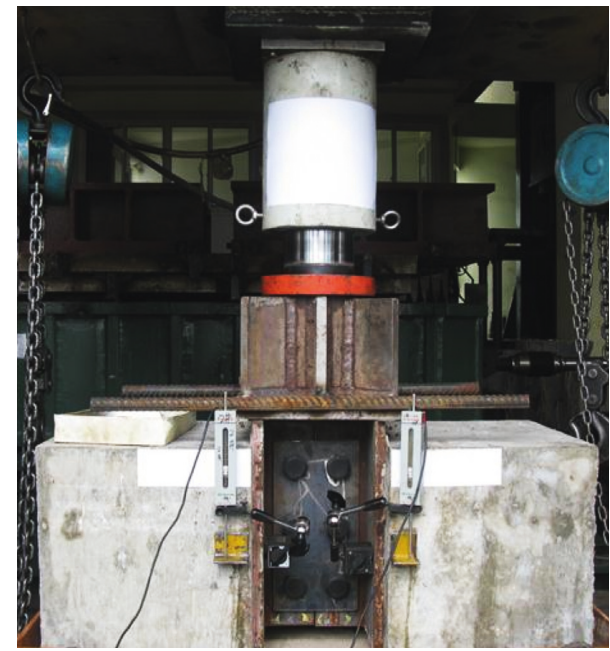

FIGURE 4: Loading setup of push-out tests.

high strength welded stud connectors when the same welding technique and concrete strength used for conventional stud connectors are employed.

3.2. Test Results. Figure 6 shows the load-slip curves for four groups of welded stud connector push-out specimens. There are three stages for the load-slip curves of welded stud connectors including initial linear stage, nonlinear or strengthening stage, and descending stage. All the welded stud connectors exhibit certain shear ductility in the nonlinear or strengthening stage since there are obvious slips at the steel-concrete interface. After reaching the ultimate shear bearing capacity, the loading force would slightly decrease under the displacement-controlled loading regime and the welded studs would fracture one by one eventually. Accordingly, the descending stage in the load-slip curves of each push-out specimen could be neglected in the further analysis of these load-slip curves.

Table 4 exhibits the final test results for each push-out specimen including their shear strength, shear stiffness, and peak slip. In this paper, shear strength refers to the ultimate shear capacity of each push-out specimen. Shear stiffness is defined as the secant modulus at the point where the applied load is half of the ultimate load on the load-slip curve for normal welded studs $[2,22]$ since load-slip curves are almost linear until that load and shear forces in welded stud connectors usually are less than half of the ultimate load at the serviceability limit state. The peak slip of the load-slip curve corresponds to the slip at the

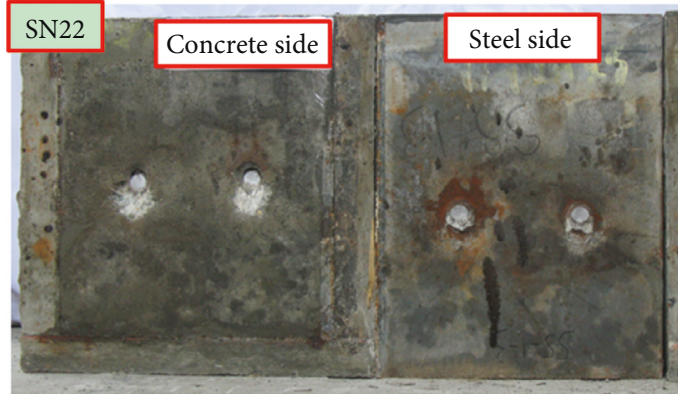

(a)

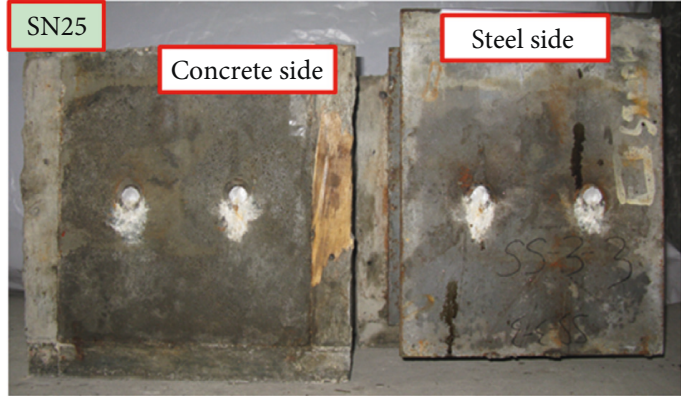

(b)

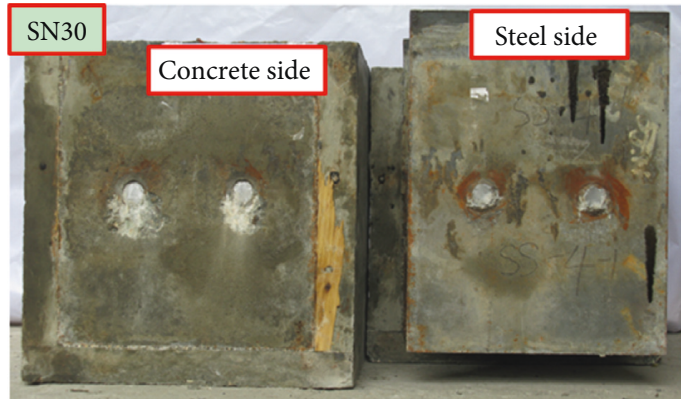

(c)

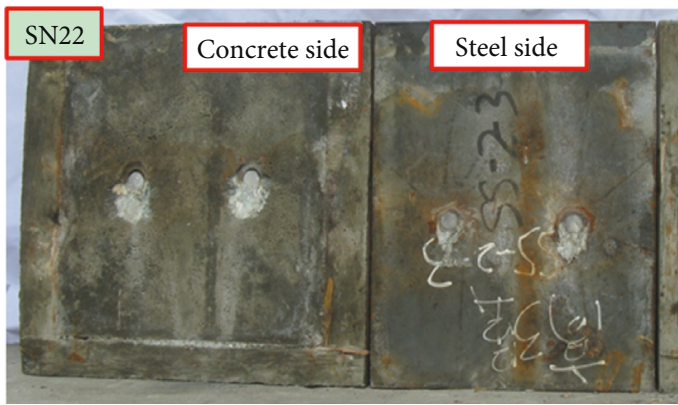

(d)

FIgURE 5: Failure modes of push-out specimens.

ultimate shear capacity. The ultimate slip of the load-slip curve may be meaningless for discussion due to the extremely short descending branch of each load-slip curve. In the following, the shear bearing capacity, peak slip, shear stiffness, and load-slip curve of four groups of welded stud push-out specimens will be discussed in detail.

3.3. Shear Strength. Figure 7 shows the shear strength distribution of four groups of welded stud connectors, in which 


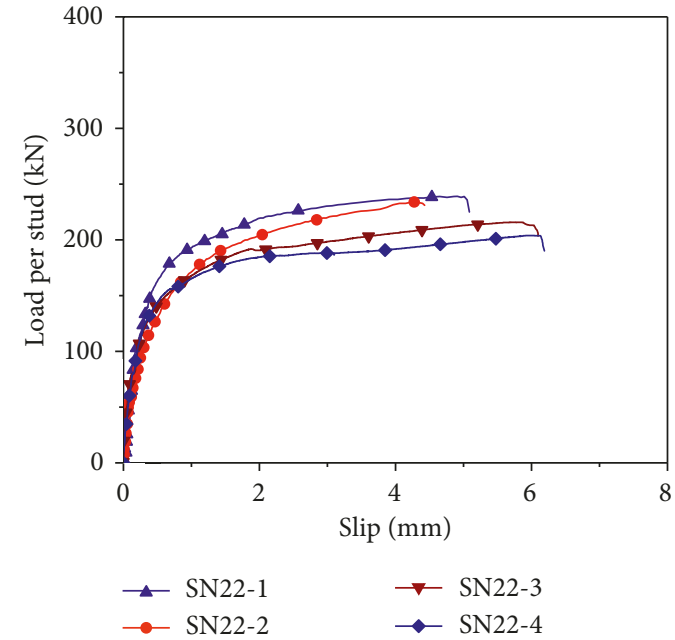

(a)

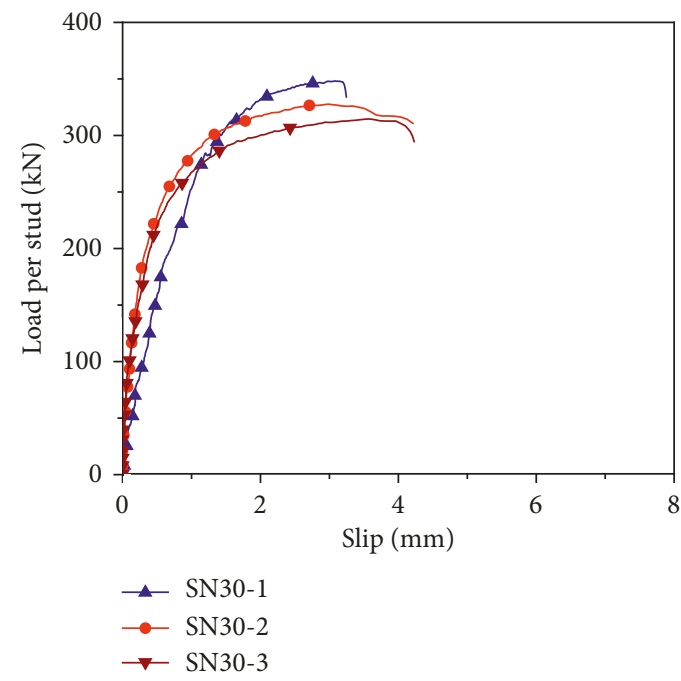

(c)

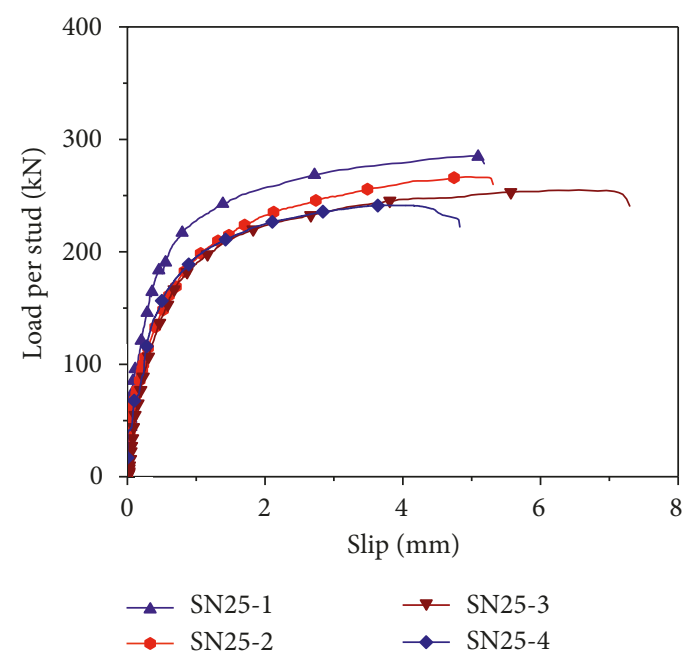

(b)

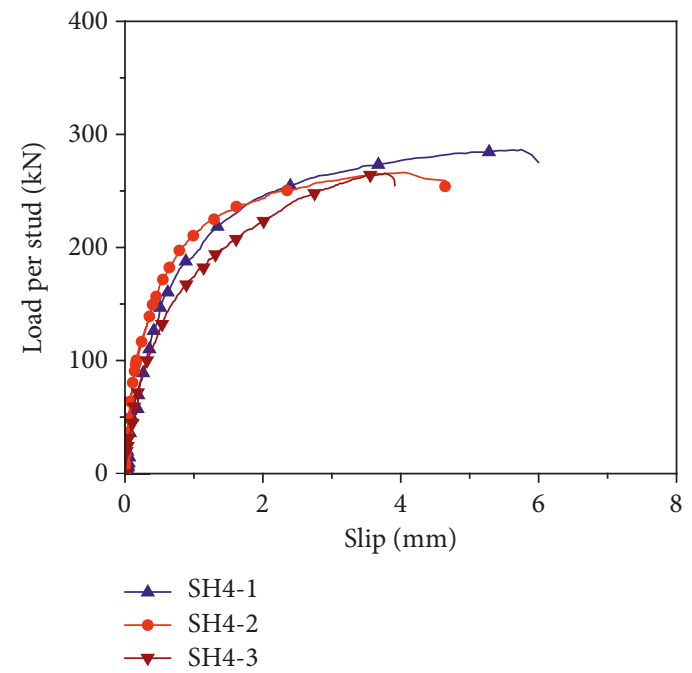

(d)

Figure 6: Load-slip curves for four groups of push-out specimens.

TABLE 4: Test results for each push-out specimen.

\begin{tabular}{|c|c|c|c|c|c|c|c|}
\hline \multirow{2}{*}{\multicolumn{2}{|c|}{ Specimen }} & \multicolumn{2}{|c|}{$\begin{array}{c}\text { Shear } \\
\text { strength }(\mathrm{kN})\end{array}$} & \multicolumn{2}{|c|}{$\begin{array}{c}\text { Shear } \\
\text { stiffness } \\
(\mathrm{kN} / \mathrm{mm})\end{array}$} & \multicolumn{2}{|c|}{$\begin{array}{l}\text { Peak slip } \\
\quad(\mathrm{mm})\end{array}$} \\
\hline & & Test & Mean & Test & Mean & Test & Mean \\
\hline \multirow{4}{*}{ SN22 } & 1 & 239 & \multirow{4}{*}{223} & 448 & \multirow{4}{*}{422} & 4.9 & \multirow{4}{*}{5.2} \\
\hline & 2 & 234 & & 300 & & 4.2 & \\
\hline & 3 & 216 & & 447 & & 5.8 & \\
\hline & 4 & 204 & & 494 & & 5.9 & \\
\hline \multirow{4}{*}{ SN25 } & 1 & 285 & \multirow{4}{*}{262} & 526 & \multirow{4}{*}{394} & 5.0 & \multirow{4}{*}{5.1} \\
\hline & 2 & 267 & & 327 & & 4.9 & \\
\hline & 3 & 255 & & 309 & & 6.6 & \\
\hline & 4 & 242 & & 415 & & 3.8 & \\
\hline \multirow{3}{*}{ SN30 } & 1 & 348 & \multirow{3}{*}{330} & 316 & \multirow{3}{*}{554} & 3.1 & \multirow{3}{*}{3.2} \\
\hline & 2 & 328 & & 727 & & 3.0 & \\
\hline & 3 & 314 & & 618 & & 3.6 & \\
\hline \multirow{3}{*}{ SH22 } & 1 & 286 & \multirow{3}{*}{273} & 284 & & 5.7 & \multirow{3}{*}{4.5} \\
\hline & 2 & 266 & & 409 & 313 & 4.1 & \\
\hline & 3 & 266 & & 246 & & 3.8 & \\
\hline
\end{tabular}

the blue symbols represent the test shear strength value and the red lines stand for the mean value. The vertical axis in Figure 7(b) indicates the shear strength ratio of these four groups of welded stud connectors to the mean shear strength of group SN22, which is $223 \mathrm{kN}$ as listed in Table 4. The average shear strengths of Group SN25, SN30, and SH22 are about $17 \%, 48 \%$, and $22 \%$ larger than that of Group SN22, respectively, which illustrates that using large diameter or high strength welded stud connectors is able to increase the shear strength of welded stud connectors. However, it should be noted that the shank cross-sectional area of welded studs in Groups SN25 and SN30 is about 29\% and $86 \%$ larger than that of Group SN22, respectively, while the tensile strength of welded studs in Group SH22 is 27\% larger than that of Group SN22.

3.4. Shear Stiffness and Peak Slip. Figure 8 shows the shear stiffness and peak slip distribution for four groups of welded 


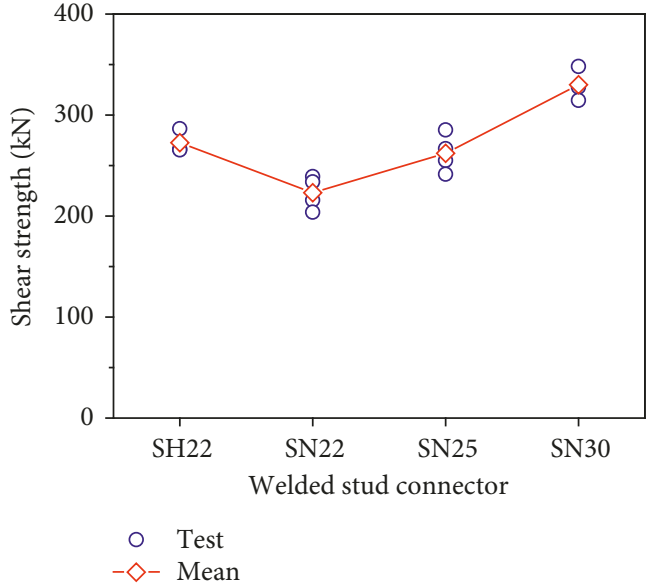

(a)

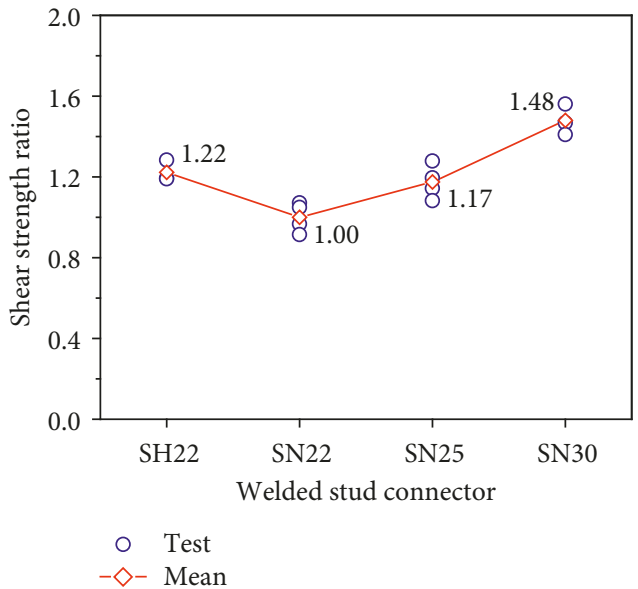

(b)

Figure 7: Shear strength distribution for four groups of push-out specimens.

stud connectors. It can be obviously seen that the test values of shear stiffness and peak slip are much more discrete than the corresponding shear strength values. Some conclusions still could be obtained from the comparison of the mean test values. It can be observed from Figure 8(a) that the average shear stiffness of Group SN30 welded stud connectors is much larger than that of other three groups, which may be produced by the larger diameter of Group SN30 welded studs. On the contrary, the average peak slip of Group SN30 welded stud connectors is less than that of other three groups as shown in Figure 8(b).

\section{Evaluation of the Push-Out Test Results}

4.1. Evaluation of Shear Strength. Both the $30 \mathrm{~mm}$ stud and the high strength stud exceed the limitation of current design codes, so the applicability of the existing design equations to large diameter and high strength studs need to be evaluated. In AASHTO LRFD [19], the design strength of one stud connector can be determined by the following equation:

$$
Q_{\mathrm{u}}=\phi 0.5 A_{\mathrm{s}} \sqrt{E_{\mathrm{c}} f_{\mathrm{c}}^{\prime}} \leq \phi A_{\mathrm{s}} f_{\mathrm{u}},
$$

where $Q_{u}$ is the nominal shear strength of the welded stud connector (N), $A_{s}$ is the cross-sectional area of stud shank $\left(\mathrm{mm}^{2}\right), E_{\mathrm{c}}$ is the elastic modulus of concrete $(\mathrm{MPa}), f_{\mathrm{c}}^{\prime}$ is the characteristic cylinder compressive strength of concrete (MPa), the nominal tensile strength of welded studs $f_{\mathrm{u}}$ is $415 \mathrm{MPa}$, and the resistance factor $\phi$ for welded stud connectors equals 0.85 .

EN 1994-1-1 [18] specifies the design strength of one stud connector given by the following equation:

$$
Q_{\mathrm{u}}=\min \left\{\frac{0.29 \alpha d^{2} \sqrt{E_{\mathrm{c}} f_{\mathrm{c}}^{\prime}}}{\gamma_{\mathrm{v}}}, \frac{0.8 A_{\mathrm{s}} f_{\mathrm{u}}}{\gamma_{\mathrm{v}}}\right\},
$$

where $d$ is the diameter of the stud shank ( $\mathrm{mm})$, which is specified between $16 \mathrm{~mm}$ and $25 \mathrm{~mm}, \alpha$ is equal to 1.0 when the overall stud height is larger than four times of its diameter, the tensile strength of the stud material $f_{\mathrm{u}}$ is specified no greater than $500 \mathrm{MPa}$ according to EN 1994-11 [18], the recommended value for the partial factor $\gamma_{\mathrm{v}}$ is 1.25 , and other variables have the same meaning with Equation (1).

GB 50017 [23] provides Equation (3) to estimate the shear strength of welded stud connectors:

$$
Q_{\mathrm{u}}=0.43 A_{\mathrm{s}} \sqrt{E_{\mathrm{c}} f_{\mathrm{c}}} \leq 0.7 A_{\mathrm{s}} f_{\mathrm{u}},
$$

where $f_{c}$ is the characteristic compressive strength of concrete prisms $(\mathrm{MPa})$ and other variables have the same meaning with Equation (1). In GB 50017 [23], the resistance factor $\phi$ or the partial factor $\gamma_{\mathrm{v}}$ for the shear strength of welded stud connectors is not clearly specified.

For the comparison of the shear strength predicted by Equations (1)-(3) with the test value, the resistance factor in Equation (1) and the partial factor in Equation (2) are not taken into account. The compressive strength of concrete prisms listed in Table 2 is used to predict the concrete cylinder compressive strength and the concrete elastic modulus. The tensile strengths of four groups of welded studs listed in Table 3 are taken into Equations (1)-(3) to predict the shear strength of welded stud connectors. It is found that the shear strength of all the test welded stud connectors is determined by the material tensile strength of welded studs rather than the compressive strength of concrete since the compressive strength of concrete blocks in the push-out specimens is up to $70 \mathrm{MPa}$ in the test day.

Figure 9 shows the shear strength comparison results among Equations (1)-(3) and the test value. Equation (1) provided in AASHTO LRFD [19] could give much accurate shear strength prediction results for large diameter and high strength welded stud connectors as well as the conventional $22 \mathrm{~mm}$ welded studs. While Equations (2) and (3) provided in EN 1994-1-1 [18] and GB 50017 [23], respectively, would result in much conservative shear strength prediction results for all the test welded stud connectors. Accordingly, the shear strength of large diameter and high strength welded 


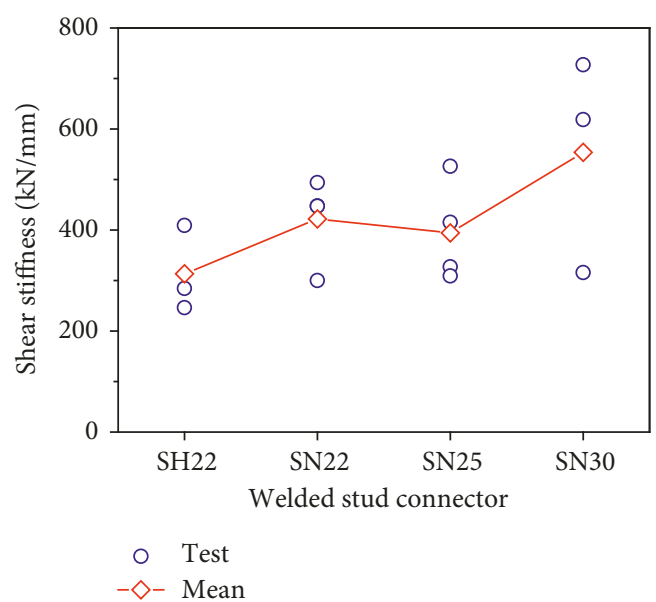

(a)

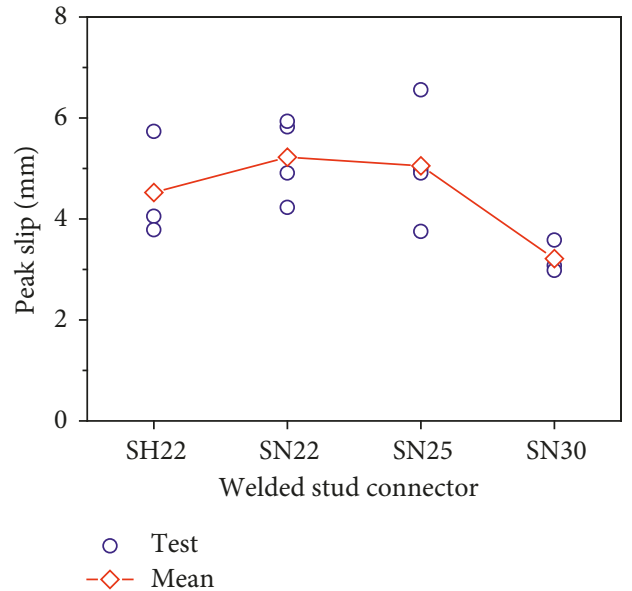

(b)

Figure 8: Shear stiffness and peak slip distribution for four groups of push-out specimens.

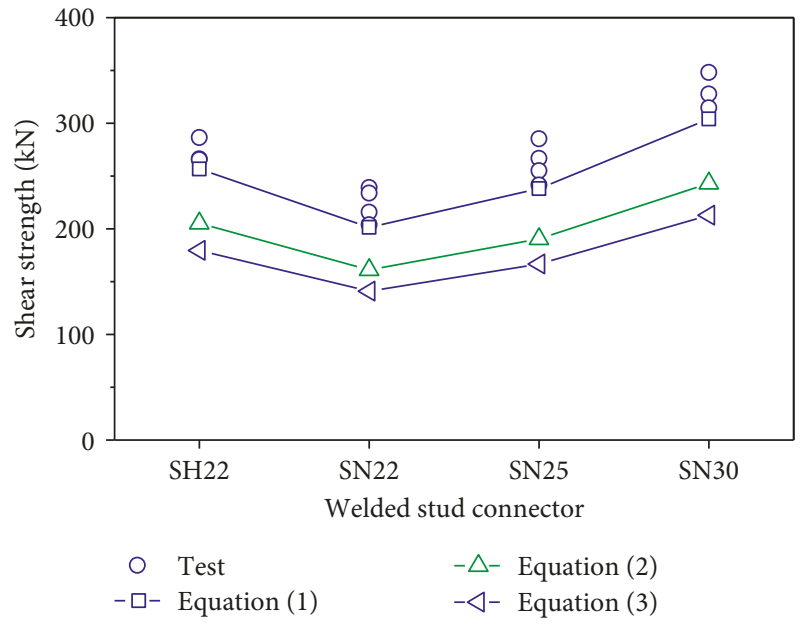

FIGURE 9: Shear strength comparison between the equation prediction and the test value.

stud connectors could also be accurately estimated by AASHTO LRFD [19] as the conventional welded stud connectors. Since the failure modes of the push-out tests are the stud shank fracture without the splitting of the concrete blocks, the shear strength of welded stud connectors could be regarded as the tensile strength of the studs, which is also verified by Pallarés and Hajjar $[4,5]$ in the research of welded stud connectors with conventional diameters.

4.2. Evaluation of Shear Stiffness. Interaction between steel and concrete elements in composite structures under service loads is mainly attributed to the bond and friction effect at the steel-concrete interface and the shear connectors. The bond and friction effect have great influences on the interaction between steel and concrete elements, and welded stud connectors carry almost no shear load before bond failure. So the behavior of shear connectors in the elastic range has negligible effect on the flexural behavior of composite beams. However, the bond effect may be damaged during the service life of a composite bridge, and friction is too complicated to be determined accurately. Accordingly, the interaction would only rely on the shear connectors to ensure the safety of composite structures, and the shear stiffness of shear connectors has great effect on the shear force distribution at the steel-concrete interface.

Previous researchers have proposed various definitions for the shear stiffness prediction of welded stud connectors. Oehlers and Coughlan [2] proposed an empirical equation to calculate the initial shear stiffness of normal stud connectors based on the experimental results, as shown in Equation (4). It is adopted by Shim et al. [16] to evaluate the shear stiffness of large diameter studs, and the results show that Equation (4) gives rather conservative predictions:

$$
k=\frac{Q_{\mathrm{u}}}{\left(0.16-0.0017 f_{\mathrm{c}}\right) d} .
$$

Lin et al. [24] proposed a semi-theoretical equation for predicting the shear stiffness of normal stud connectors based on the theory of a beam on an elastic foundation and ninety-nine test results collected from the available literature, as shown in the following equation:

$$
k=0.32 d E_{\mathrm{c}}^{0.75} E_{\mathrm{s}}^{0.25} .
$$

In Equations (4) and (5), $k$ represents the initial shear stiffness of welded stud connectors defined as the ratio of half of the shear strength to the corresponding slip $(\mathrm{N} / \mathrm{mm})$; $Q_{u}$ is the shear strength of welded stud connectors $(\mathrm{N}) ; f_{c}$ is the cylinder compressive strength of concrete ( $\mathrm{MPa})$, which could be taken as $59.8 \mathrm{MPa}$ based on the relationship between the cylinder compressive strength and the cube compressive strength proposed by Mansur and Islam [25]; $d$ is the diameter of the stud shank $(\mathrm{mm}) ; E_{\mathrm{c}}$ stands for the elastic modulus of concrete $(\mathrm{MPa})$, which could be regarded as $37.6 \mathrm{GPa}$ predicted by $E_{\mathrm{c}}=22\left[f_{\mathrm{c}} / 10\right]^{0.3}$ proposed by $\mathrm{EN}$ 1992-1-1; and $E_{\mathrm{s}}$ is the elastic modulus of the stud material $(\mathrm{MPa})$ which is equal to $2.0 \times 10^{5} \mathrm{MPa}$. 
The accuracy of Equations (4) and (5) is evaluated, as shown in Figure 10. The shear strength of welded stud connectors $Q_{\mathrm{u}}$ in Equation (4) is set to be the average shear strength of each group of welded stud connectors. It can be obviously seen from Figure 10 that Equation (5) could give more accurate predictions of the shear stiffness for large diameter and high strength welded stud connectors. While Equation (4) dramatically underestimates the shear stiffness of welded stud connectors, which is consistent with the conclusion made by Shim et al. [16].

4.3. Evaluation of Peak Slip. The peak slip of the load-slip curve $s_{\mathrm{p}}$, slip corresponding to the ultimate shear capacity, is an important parameter to evaluate the shear deformation capacity of welded stud connectors. Given that the descending branches of the load-slip curves for each pushout test are extremely short, the peak slip could also represent the ultimate slip of the load-slip curves, which is usually used to describe the ductility of welded stud connectors. Adequate ductility is very favorable to the shear force redistribution at the steel-concrete interface of composite structures. Oehlers and Coughlan [2] put forward Equation (6) to predict the peak slip of welded stud connectors:

$$
s_{\mathrm{p}}=\left(0.480-0.0042 f_{\mathrm{c}}\right) d .
$$

The International Federation for Structural Concrete [26] suggests the following equation to calculate the peak slip of welded stud connectors:

$$
s_{\mathrm{p}}=\left(0.389-0.0023 f_{\mathrm{c}}\right) d .
$$

In Equations (6) and (7), $f_{\mathrm{c}}$ is the cylinder compressive strength of concrete which is equal to $59.8 \mathrm{MPa}$ and $d$ stands for the diameter of the stud shank (mm).

Figure 11 demonstrates the peak slip comparison results among Equations (6) and (7) and the test value. The peak slips of welded stud connectors embedded in the identical strength concrete would increase with the increment of the stud shank diameter according to both Equations (6) and (7), while the test values for four groups of welded stud connectors as listed in Table 4 and shown in Figure 11 do not exhibit the same tendency. The average peak slip of Group SN25 welded stud connectors is almost equal to that of Group SN22 welded stud connectors, while the peak slips of Group SN30 welded stud connectors would be dramatically overestimated based on Equations (6) or (7). The average peak slip of Group SN30 is only $3.2 \mathrm{~mm}$, which is less than the predicted peak slip based on Equations (6) or (7). The test peak slips of welded stud connectors with large diameter are consistent with the test results conducted by Badie et al. [15], which exhibited that the peak slips of welded stud connector with $31.8 \mathrm{~mm}$ diameter would decrease about $30 \%$ compared with conventional $22 \mathrm{~mm}$ welded stud connectors. The peak slips of Group SH22 with the high strength stud material have a lower value compared with those of Group SN22 since the high strength stud material can result in a lower elongation, which has a significant effect on the ductility of welded stud

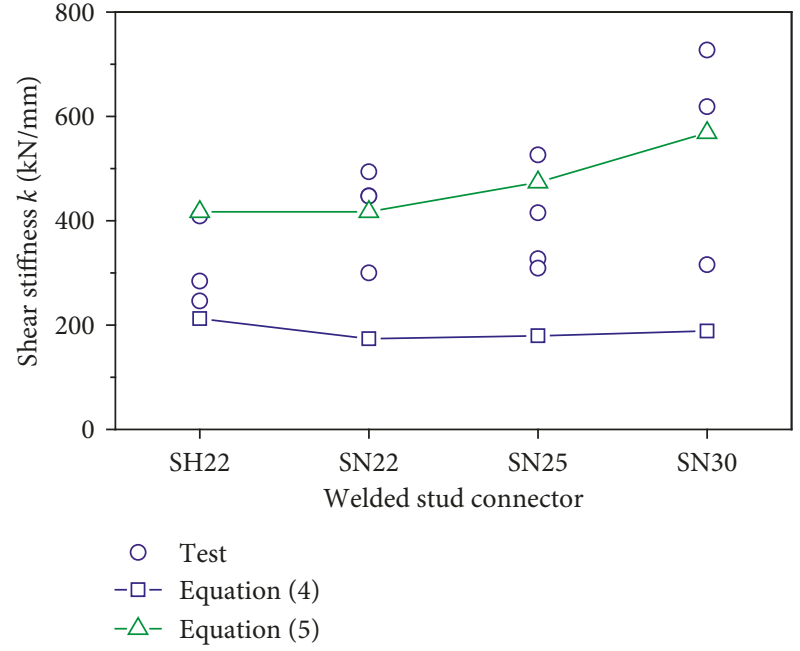

FIGURE 10: Shear stiffness comparison between the equation prediction and the test value.

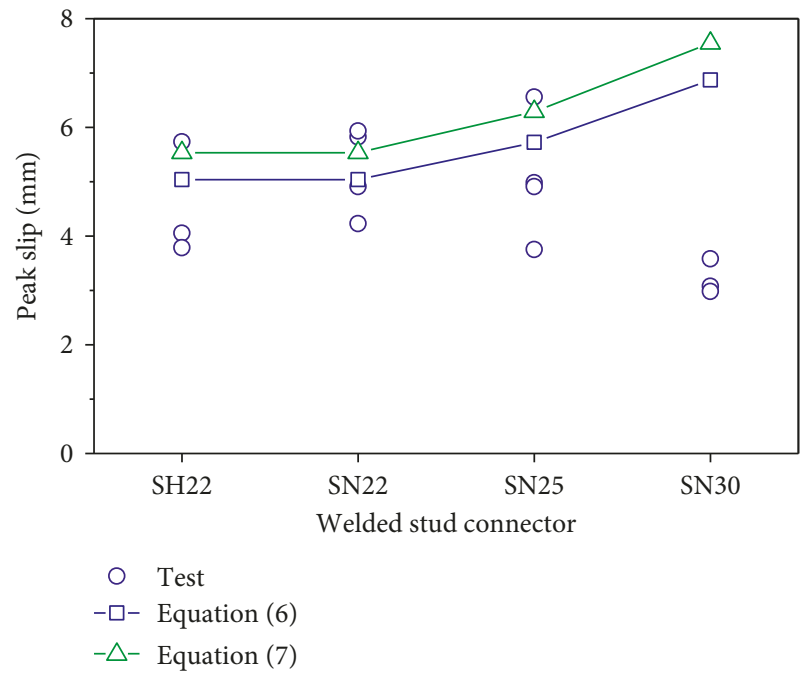

FIGURE 11: Peak slip comparison between the equation prediction and the test value.

connectors. Accordingly, it can be concluded that Equations (6) and (7) could only be employed in the peak slip prediction of welded stud connectors with diameter less than $25 \mathrm{~mm}$, and Equation (6) could produce a relatively accurate prediction results when the concrete strength are much higher. In spite of above discussion, it still can be seen that the test results from different research studies lack consistency and thus more experimental studies should be performed on the large diameter and high strength welded stud connectors in order to ensure their safe application in composite structures.

4.4. Evaluation of Load-Slip Curve. Load-slip relationship can reflect the nonlinear behavior of welded stud connectors at the ultimate limit state. An expression capable of describing the load-slip curve accurately is indispensable for the nonlinear analysis of steel-concrete composite structures 


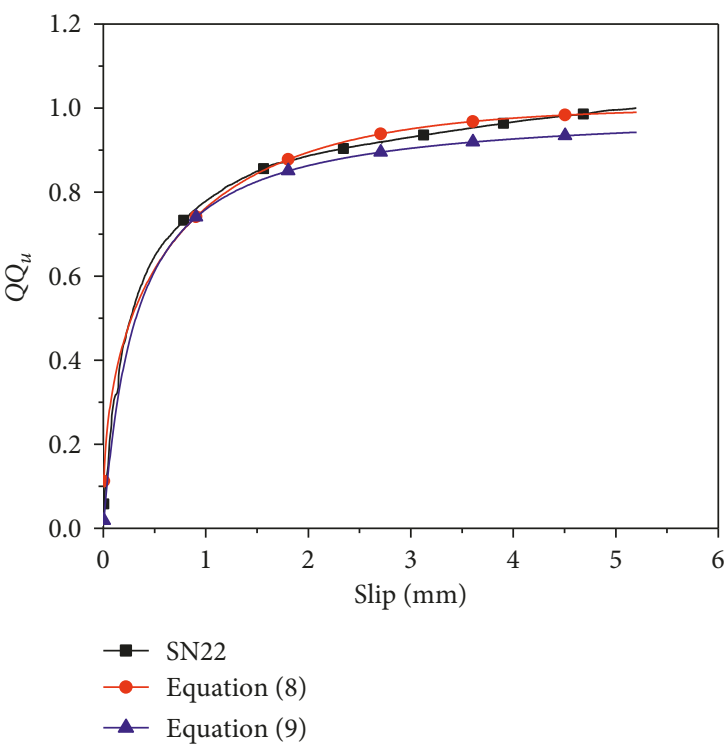

(a)

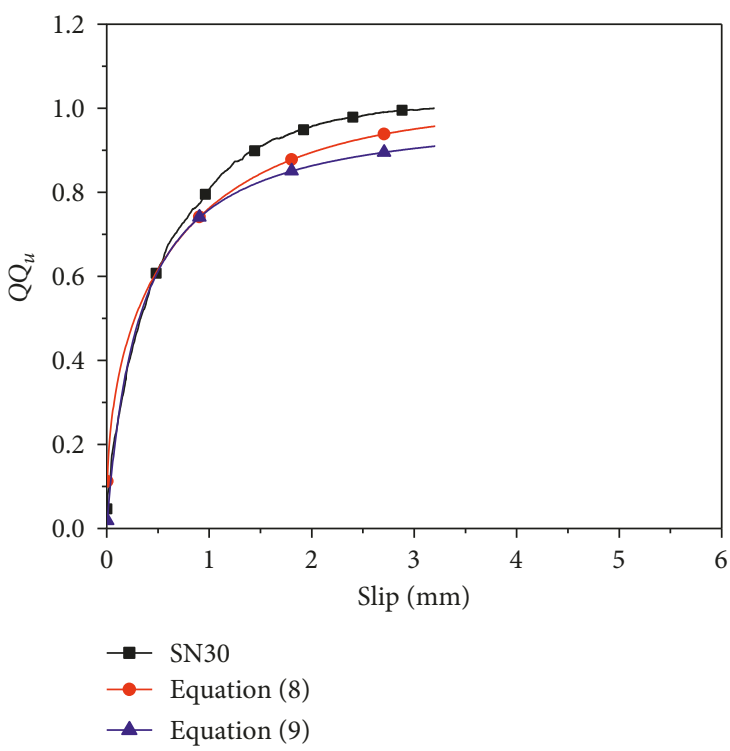

(c)

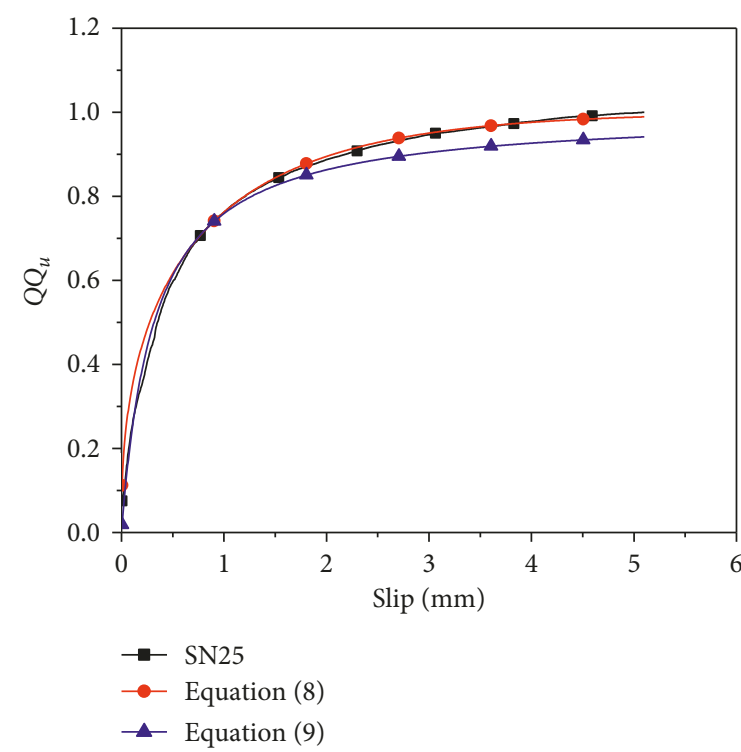

(b)

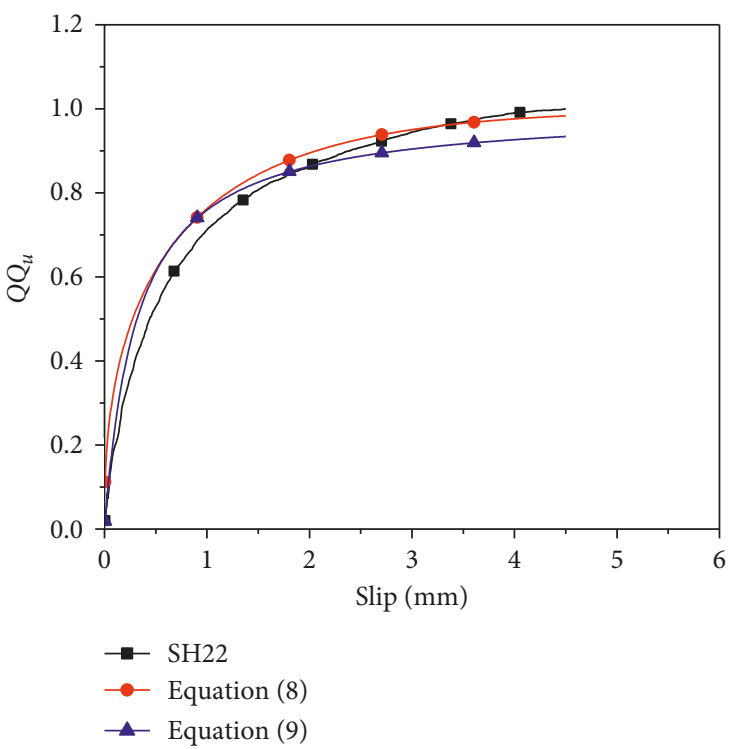

(d)

FIGURE 12: Load-slip curve comparison between the equation relationship and the test curve.

connected by welded stud connectors. The expressions of load-slip relationships for large diameter and high strength welded stud connectors are not examined before. Thus, it is necessary to investigate the applicability of the existing loadslip relationships to large diameter and high strength welded stud connectors.

Ollgaard et al. [1] proposed an empirical formula for the load-slip curve of conventional welded stud connectors under continuous loading:

$$
\frac{\mathrm{Q}}{Q_{\mathrm{u}}}=\left(1-e^{-0.71 S}\right)^{0.4} .
$$

Much earlier, Buttry [27] put forward a fractional formula for the load-slip curve of conventional welded stud connectors:

$$
\frac{Q}{Q_{u}}=\frac{3.15 S}{(1+3.15 S)} .
$$

In Equations (8) and (9), $S$ is the slip value of welded stud connectors $(\mathrm{mm})$ and $Q / Q_{u}$ stands for the ratio of the loading force to the shear strength of welded stud connectors.

For comparing the test load-slip curves of four groups of welded stud connectors with the fitting load-slip curves by Equations (8) and (9), the average load-slip curves of each group of welded stud connectors are computed based on the average shear strength and peak slip of each group of welded stud connectors as listed in Table 4 . The final load-slip curve comparison results among the test curves and prediction results by Equations (8) and (9) are depicted in Figure 12. 
It can be obviously seen from Figure 12 that both Equations (8) and (9) could not only describe the load-slip curve of Group SN22 conventional welded stud connectors accurately but also give acceptable prediction results for Group SN25 and Group SN30 large diameter welded stud connectors and Group SH22 high strength welded stud connectors. Additionally, Equation (8) will predict the nonlinear part of the load-slip curves much well, while Equation (9) will produce a much accurate result for the initial or linear part of the load-slip curves for all groups of welded stud connectors. Consequently, both Equations (8) and (9) can be used to predict the load-slip curves of large diameter and high strength welded stud connectors for the nonlinear structural analysis of composite structures.

\section{Conclusion}

In this research, fourteen push-out tests were carried out to investigate the shear performance of large diameter and high strength welded stud connectors. The shear strength, shear stiffness, peak slip, and load-slip relationship of these welded stud connectors were examined and compared with the existing design codes or prediction equations. The following conclusions can be drawn:

(1) The ductile failure mode could be achieved for large diameter and high strength welded stud connectors when the same welding technique and concrete strength used for conventional welded stud connectors are employed.

(2) The average shear strength of Group SN25, SN30, and $\mathrm{SH} 22$ welded stud connectors are about $17 \%$, $48 \%$, and $22 \%$ larger than that of Group SN22, respectively, confirming that using large diameter or high strength welded studs increases the shear strength of a welded stud connector. The shear strength of large diameter and high strength welded stud connectors could be accurately estimated by AASHTO LRFD [19] as the conventional welded stud connectors.

(3) The shear stiffness equation proposed by Lin et al. could give much accurate and reasonable shear stiffness prediction for welded stud connectors including large diameter and high strength welded stud connectors.

(4) The existing peak slip prediction equations could only be employed in the welded stud connectors with diameter less than $25 \mathrm{~mm}$, and the peak slip prediction equation proposed by Oehlers and Coughlan could produce relatively accurate results when the concrete strength is much higher.

(5) The existing load-slip relationships proposed by Ollgaard and Buttry could not only describe the load-slip curve of Group SN22 welded stud connectors accurately but also give acceptable prediction results for Group SN25 and Group SN30 large diameter welded stud connectors and Group SH22 high strength welded stud connectors.
(6) Since the push-out tests on the large diameter and high strength welded stud connectors are rather limited in this paper, a detailed parametric analysis on the shear performance of these welded stud connectors using the finite element analysis method is underway.

\section{Data Availability}

The load-slip curve data of the push-out tests in this paper are available from the corresponding author upon request.

\section{Conflicts of Interest}

The authors declare that they have no conflicts of interest.

\section{Acknowledgments}

This work was financially supported by the National Natural Science Foundation (Grant no. 51578406) of People's Republic of China.

\section{References}

[1] J. G. Ollgaard, R. G. Slutter, and J. W. Fisher, "Shear strength of stud connectors in lightweight and normal-weight concrete," AISC Engineering Journal, vol. 8, no. 2, pp. 55-64, 1971.

[2] D. J. Oehlers and C. G. Coughlan, "The shear stiffness of stud shear connections in composite beams," Journal of Constructional Steel Research, vol. 6, no. 4, pp. 273-284, 1986.

[3] D. Lam, "Capacities of headed stud shear connectors in composite steel beams with precast hollowcore slabs," Journal of Constructional Steel Research, vol. 63, no. 9, pp. 1160-1174, 2007.

[4] L. Pallarés and J. F. Hajjar, "Headed steel stud anchors in composite structures, Part I: shear," Journal of Constructional Steel Research, vol. 66, no. 2, pp. 198-212, 2010.

[5] L. Pallarés and J. F. Hajjar, "Headed steel stud anchors in composite structures, Part II: tension and interaction," Journal of Constructional Steel Research, vol. 66, no. 2, pp. 213-228, 2010.

[6] Z. Lin, Y. Liu, and J. He, "Behavior of stud connectors under combined shear and tension loads," Engineering Structures, vol. 81, pp. 362-376, 2014.

[7] R. Liu and Y. Liu, "Analysis of auxiliary ribs in steel-concrete joint of hybrid girder," Journal of Constructional Steel Research, vol. 112, pp. 363-372, 2015.

[8] S. H. Kim, J. H. Yoon, J. H. Kim, W. J. Choi, and J. H. Ahn, "Structural details of steel girder-abutment joints in integral bridges: an experimental study," Journal of Constructional Steel Research, vol. 70, pp. 190-212, 2012.

[9] R. M. Lawson, J. Lim, S. J. Hicks, and W. I. Simms, "Design of composite asymmetric cellular beams and beams with large web openings," Journal of Constructional Steel Research, vol. 62, no. 6, pp. 614-629, 2006.

[10] R. M. Lawson, J. B. P. Lim, and S. O. Popo-Ola, "Pull-out forces in shear connectors in composite beams with large web openings," Journal of Constructional Steel Research, vol. 87, no. 6, pp. 48-59, 2013.

[11] H. Svensson, Cable-Stayed Bridges: 40 Years of Experience Worldwide, John Wiley \& Sons, Hoboken, NJ, USA, 2013.

[12] S. Zheng, Y. Liu, and H. Xu, "Connection behaviour of cablepylon anchorage with steel bracket and anchor beam," in 
Proceedings of the 4th International Symposium on Life-Cycle Civil Engineering (IALCCE 2014), Tokyo, Japan, 2014.

[13] D. Xue, Y. Liu, Z. Yu, and J. He, "Static behavior of multi-stud shear connectors for steel-concrete composite bridge," Journal of Constructional Steel Research, vol. 74, pp. 1-7, 2012.

[14] Z. Lin, Y. Liu, and J. He, "Static behaviour of lying multi-stud connectors in cable-pylon anchorage zone," Steel and Composite Structures, vol. 18, no. 6, pp. 1369-1389, 2015.

[15] S. S. Badie, M. K. Tadros, H. F. Kakish, D. L. Splittgerber, and M. C. Baishya, "Large shear studs for composite action in steel bridge girders," Journal of Bridge Engineering, vol. 7, no. 3, pp. 195-203, 2002.

[16] C. S. Shim, P. G. Lee, and T. Y. Yoon, "Static behavior of large stud shear connectors," Engineering Structures, vol. 26, no. 12, pp. 1853-1860, 2004.

[17] P. G. Lee, C. S. Shim, and S. P. Chang, "Static and fatigue behavior of large stud shear connectors for steel-concrete composite bridges," Journal of Constructional Steel Research, vol. 61, no. 9, pp. 1270-1285, 2005.

[18] EN 1994-1-1: 2004, Eurocode 4: Design of Composite Steel and Concrete Structures, Part 1-1: General Rules and Rules for Buildings, European Committee for Standardization (CEN), Brussels, Belgium, 2004.

[19] AASHTO, AASHTO LFRD Bridge Design Specifications, American Associate of State Highway and Transportation Officials, Washington, DC, USA, 4th edition, 2007.

[20] H. T. Nguyen and S. E. Kim, "Finite element modeling of push-out tests for large stud shear connectors," Journal of Constructional Steel Research, vol. 65, no. 10-11, pp. 19091920, 2009.

[21] GB/T 10433-2002, Cheese Head Studs for Arc Stud Welding, China Standards Press, Beijing, China, 2002, in Chinsese.

[22] R. P. Johnson and I. M. May, "Partial-interaction design of composite beams," Structure Engineering, vol. 53, no. 8, pp. 305-311, 1975.

[23] GB 50017-2017, Code for Design of Steel Structures, Ministry of Housing and Urban-rural Development of Peoples' Republic of China, Beijing, China, 2017, in Chinese.

[24] Z. Lin, Y. Liu, and J. He, "Research on calculation method of shear stiffness for headed stud connectors," Engineering Mechanics, vol. 31, no. 7, pp. 85-90, 2014, in Chinsese.

[25] M. A. Mansur and M. M. Islam, "Interpretation of concrete strength for nonstandard specimens," Journal of Materials in Civil Engineering, vol. 14, no. 2, pp. 151-155, 2002.

[26] FIP, FIP Bulletin 55: Model Code 2010, First Complete DraftVolume 1, International Federation for Structural Concrete (FIB), Lausanne, Switzerland, 2010.

[27] K. E. Buttry, Behavior of stud shear connectors in lightweight and normal-weight concrete, Ph.D. thesis, University of Missouri, Rolla, MO, USA, 1965. 


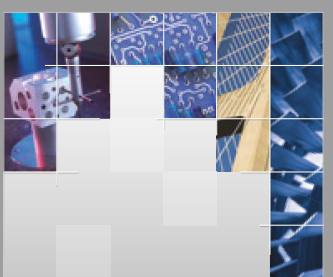

\section{Enfincering}
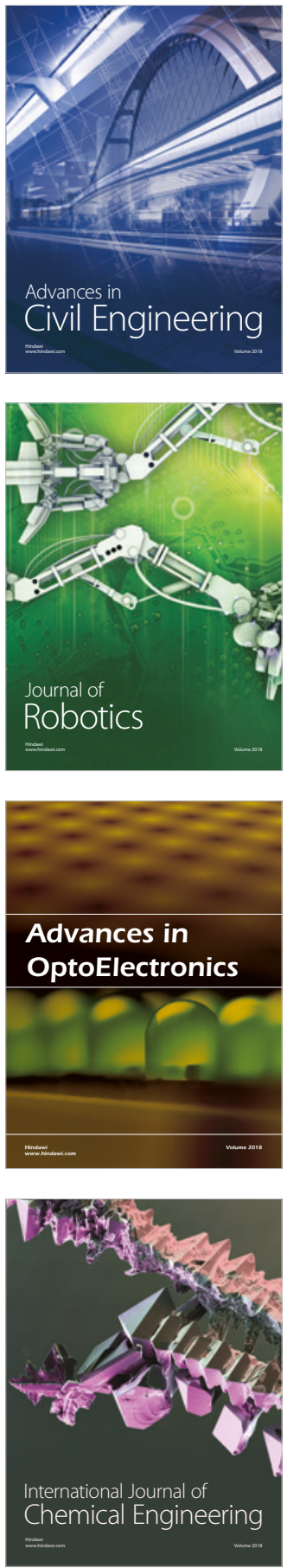

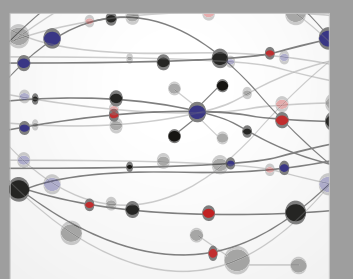

\section{Rotating \\ Machinery}

The Scientific World Journal

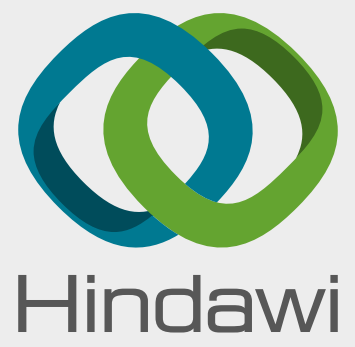

Submit your manuscripts at

www.hindawi.com
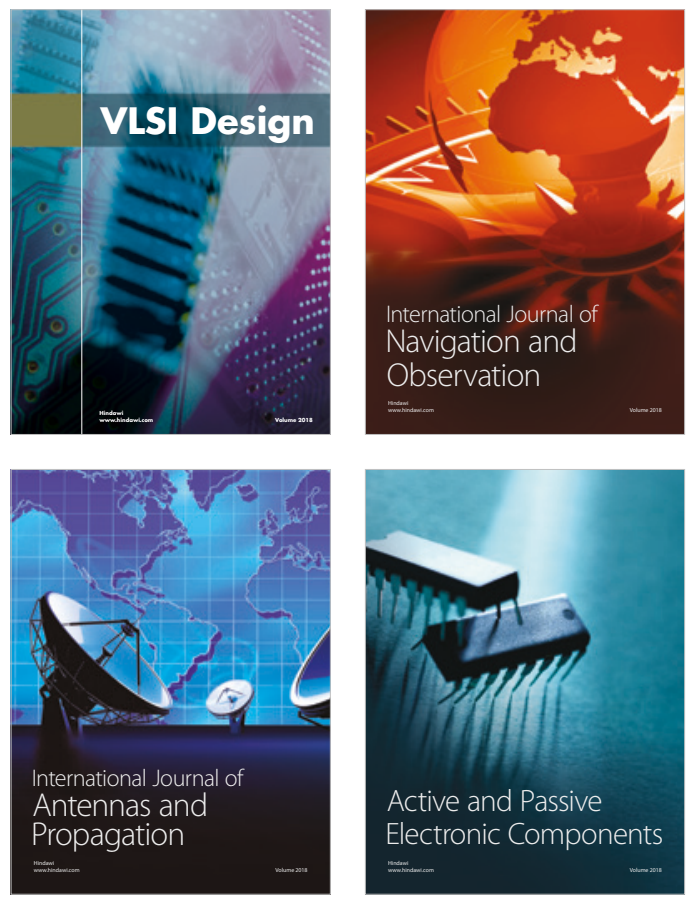
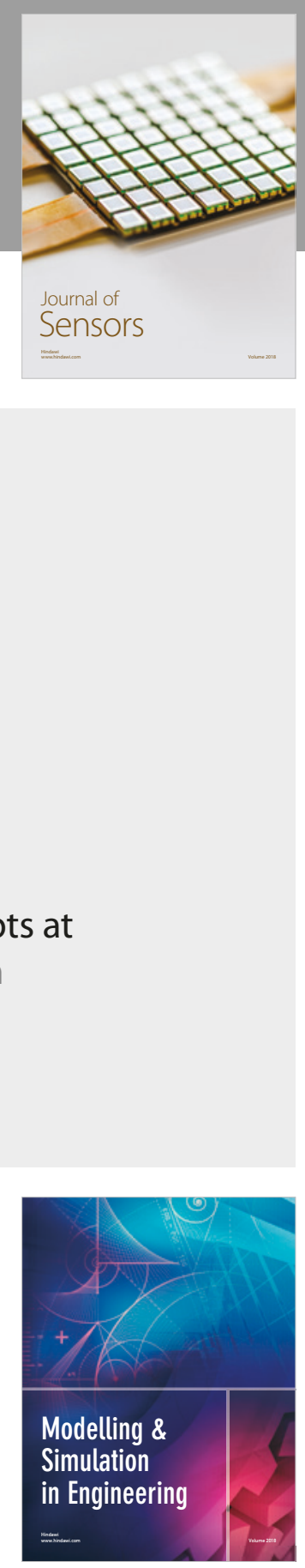

\section{Advances \\ Multimedia}
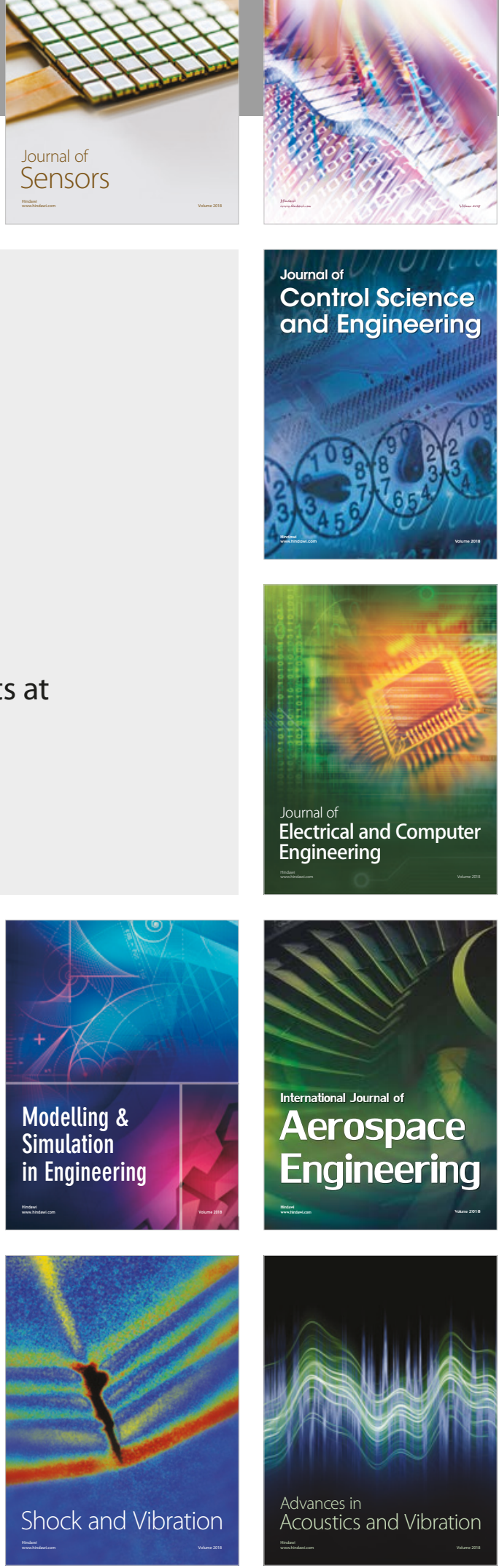